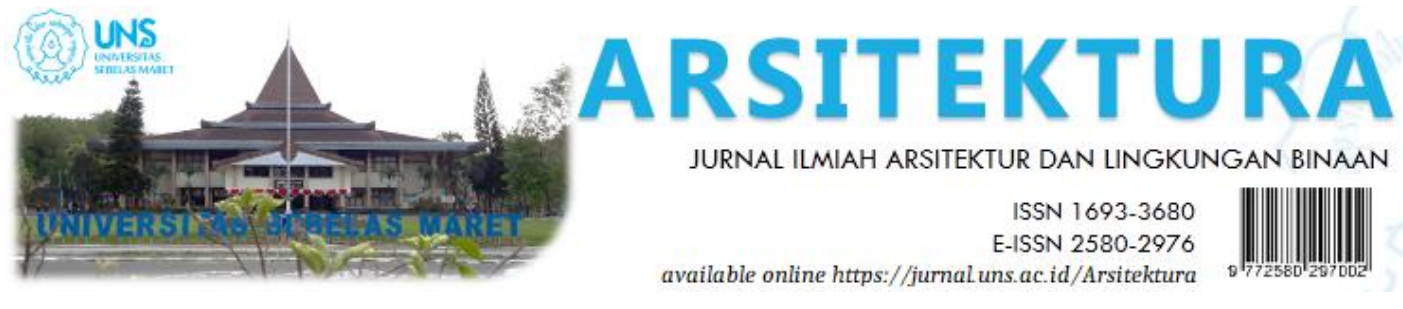

Volume 18 Issue 2 October 2020, pages:265-276

\title{
Studi Konfigurasi Ruang Mall \\ (Studi Kasus: Matahari Mall dan Ayani Megamall di Pontianak)
}

\section{Study on Spatial Configuration of Mall (Study Case: Matahari Mall and Ayani Megamall in Pontianak)}

\author{
Andi $^{1 *}$, Zairin Zain ${ }^{2}$, Uray Fery Andi ${ }^{3}$ \\ Mahasiswa S-1 Program Studi Arsitektur, Fakultas Teknik, Universitas Tanjungpura ${ }^{1 *}$ \\ Email: andizhangnd@gmail.com \\ Staf Pengajar Juru san Arsitektur, Fa kultas Teknik, Universitas Tanjungpura ${ }^{2,3}$
}

DOI: https://doi.org/10.20961/arst.v18i2.43471

Received: August 3, 2020 Revised: September 13, 2020 Accepted: September 18, 2020 Available online: October 31, 2020

\begin{abstract}
Mall is a commercialbuilding that prioritizes pedestrian conceptand spatial relation. The assessment of spatial relation can be analyzed by using space syntaxmethod. There is a significant difference in the visitor rate between Matahari Mall and Ayani Me gamall which gives rise to a hypothesis that the spatial configuration affects the success of the mall. The purpose of this study is to determine the problems that exist in spatial configuration of the mall. This research uses a sequential explanatory approach that combines the space syntax method (choice simulation and gate count observation) with grounded theory analysis. Grounded theory analysis is done by comparing space syntax data with the theory of the mall. The data is analyzed with correlation analysis, to see the similitude of simulation data with field data. The result of this study is Ayani Megamall as the one with higher visitor rate has a better organized spatial configuration than Matahari Mall. This result has proven the hypothesis that spatial configuration affects the success of mall. The spatial configuration problems found are the placement of anchor, retail, and elevator which unable to support the visitor's movement to all places.
\end{abstract}

Keywords: mall, spatial configuration, space syntax, choice, gate count

\section{PENDAHULUAN}

Mal merupakan fungsi bangunan yang dipopulerkan oleh Victor Gruen sebagai tempat berbelanja dengan konsep area pedestrian pada masa 1950-an (Gregg, 2019). Konsep ini sudah ada sejak abad pertengahan dalam wujud kawasan pasar tradisional terbuka dengan arah muka toko yang berbaris menghadap ke jalur pedestrian (Moghimi \& Assari, 2016). Pada masa modern, implementasi konsep pedestrian pada mal terbukti efektif dan berhasil meningkatkan perekonomian mal (Malherek, 2019).

Tingkat keberhasilan implementasi konsep pedestrian mal dapat dinilai dengan melakukan studi pada konfigurasi ruang pedestriannya. Studi terdahulu mengenai konfigurasi ruang mal telah dilakukan oleh Mustafa (2017) dengan teknik pengumpulan data kuesioner tingkat kepuasan pengunjung tentang mal. Berbeda dengan studi terdahulu, studi ini menggunakan metode metode space syntax. 
Space syntax ditemukan oleh Hillier dan Hanson dengan tujuan mengembangkan pemahaman kinerja ruang yang berkaitan dengan pergerakan pengguna ruang dalam sebuah konfigurasi ruang (Barada \& Mutiari, 2013). Space syntax dapat menganalisis preferensi sirkulasi pengunjung dan menilai sirkulasi pedestrian mal dengan simulasi choice (Nes \& Yamu, 2018).

Berdasarkan ruang sirkulasinya, mal dibedakan menjadi mal dengan sirkulasi enclosed dan mal dengan sirkulasi open plan (GSA, 2012). Total jumlah mal di Kota Pontianak dan sekitarnya adalah 4 mal. Dua diantaranya adalah Matahari Mall dan Ayani Megamall. Kedua mal ini memiliki sirkulasi pedestrian yang bersekat (enclosed), batas jelas antar ruang, dan tokotokonya memiliki muka toko (Gambar 1 kiri) (GSA, 2012). Sebaliknya, dua mal lainnya memiliki sirkulasi pedestrian yang terbuka (open plan) dengan toko-tokonya yang bergabung tanpa sekat dan tanpa muka toko (Gambar 1 kanan) (GSA, 2012). Dua mal ini adalah Ramayana Mall dan Trans Mart. Dalam studi ini, mal yang diperlukan adalah mal yang memiliki elemen-elemen yang berupa jalur pedestrian, sekat ruang yang jelas, dan area muka toko. Sehubungan dengan itu, Matahari Mall dan Ayani Megamall menjadi mal yang lebih sesuai sebagai objek studi konfigurasi ruang mal.

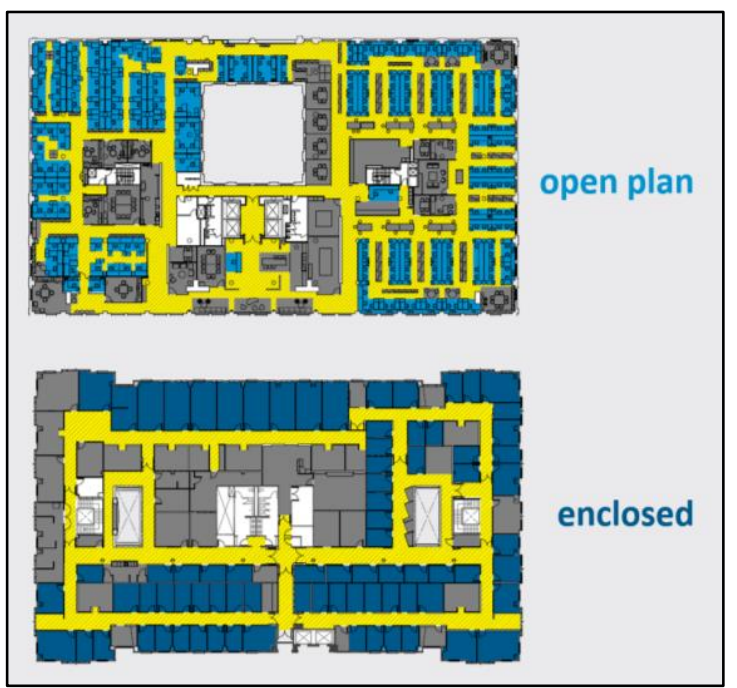

Gambar 1. Sistem Sirkulasi Open Plan dan enclosed

Sumber: GSA, 2012.

Perbandingan jumlah pengunjung antara Matahari Mall dan Ayani Megamall adalah jumlah pengunjung Ayani Megamall 16 kali lebih banyak dari jumlah pengunjung Matahari Mall (Lihat Gambar 2). Bila daya tampung (luas Gross Floor Area) mal ditambahkan sebagai faktor dalam perbandingan jumlah pengunjung, Ayani Megamall tetap saja lebih ramai dikunjungi dengan perbandingan 6 kali dari jumlah pengunjung Matahari Mall. Perbedaan jumlah pengunjung ini membuat kedua mal ini menarik untuk diteliti. Kondisi tersebut memunculkan sebuah hipotesis bahwa konfigurasi ruang pedestrian Ayani megamall terkonsep dan terimplementasi lebih baik daripada Matahari Mall. Hipotesis ini didasari oleh pentingnya ruang pedestrian dalam perancangan mall.

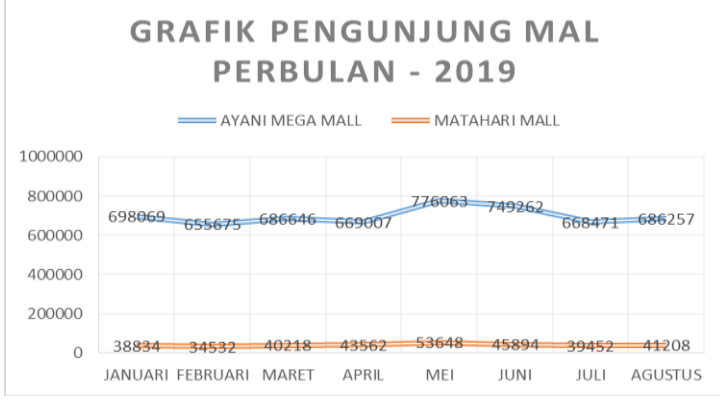

Gambar 2. Grafik Pengunjung MalPer Bulan

Berdasarkan isu-isu di atas, masalah studi yang dapat dirumuskan adalah tentang wujud implementasi konsep pedestrian pada konfigurasi ruang di dua mal tersebut dengan menggunakan metode space syntax. Tujuan studi ini adalah untuk mengetahui masalah pada konfigurasi ruang Matahari Mall dan Ayani Megamall, serta untuk menguji peran konfigurasi ruang pedestrian dalam keberhasilan mall. Studi ini diharapkan dapat menjadi rekomendasi atau pedoman untuk perancangan mal yang lebih baik.

\subsection{Analisis Space syntax}

Analisis space syntax memiliki beberapa jenis representasi ruang yang terdiri dari axial map, convex map, isovist, dan visual graph analysis. Mereka dipilih berdasarkan skala target analisis yang ingin direpresentasikan (Pinelo \& Turner, 2010). Dalam skala bangunan, convex map merupakan pilihan utama yang paling cocok. Convex map adalah peta representasi ruang yang menggambarkan ruang dalam poligon convex space. Convex space merupakan batas imajiner ruang yang menuruti aturan convexity. 
Convexity adalah kondisi saat sebuah garis lurus ditarik dari suatu titik ke titik lain dalam sebuah ruang tanpa keluar dari batas ruang tersebut (Hillier \& Hanson, 2003) (Lihat Gambar 3).

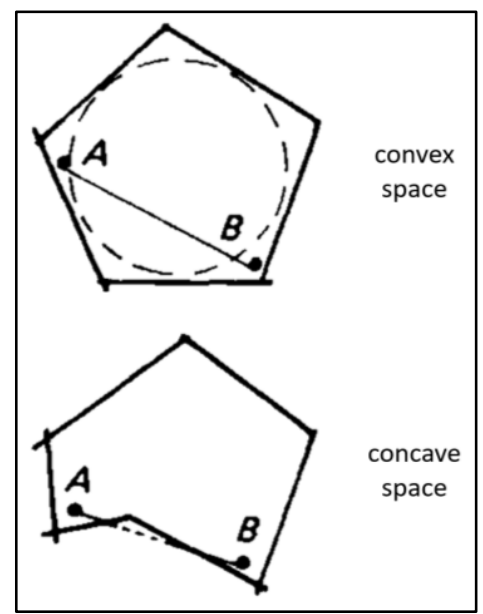

Gambar 3: Convexspace (atas) dan concave space (bawah)

Sumber:Hillier \& Hanson, 2003.

Space syntax memiliki beberapa macam analisis yang terdiri dari connectivity, integration, choice, dan intelligibility (Al_Sayed, 2018). Analisis-analisis ini dipilih berdasarkan tujuan dan jenis pemahaman ruang yang ingin dicari (Hillier \& Hanson, 2003). Penelitian ini ingin melihat preferensi pergerakan pengunjung sehingga menggunakan analisis choice. Dalam teori space syntax, pengunjung cenderung memilih rute yang paling memungkinkan untuk menghindari kerumitan dalam menuju destinasi (Hillier \& Hanson, 2003). Preferensi ini adalah perilaku pengunjung yang diukur dalam nilai choice. Dalam convex map, choice membantu memprediksi potensi okupansi sebuah ruang. Analisis choice dihitung dengan kombinasi dari 3 tipe analisis, yaitu metric, topological, dan angular (Turner, 2008). Masing-masing analisis mendefinisikan "jalur terpendek" dengan cara yang berbeda. Analisis metric mendefinisikan jalur terpendek sebagai unit panjang (length) yaitu jarak tempuh terpendek (Turner, 2008) (Lihat Gambar 4 atas). Analisis topological mendefinisikan jalur terpendek sebagai jumlah belokan (turn) yang dilakukan yaitu belokan tersedikit (Turner, 2008) (Lihat Gambar 4 kiri). Analisis angular mendefinisikan jalur terpendek sebagai unit sudut (angle) yaitu sudut belokan terkecil (Turner, 2008) (Lihat Gambar 4 kanan).

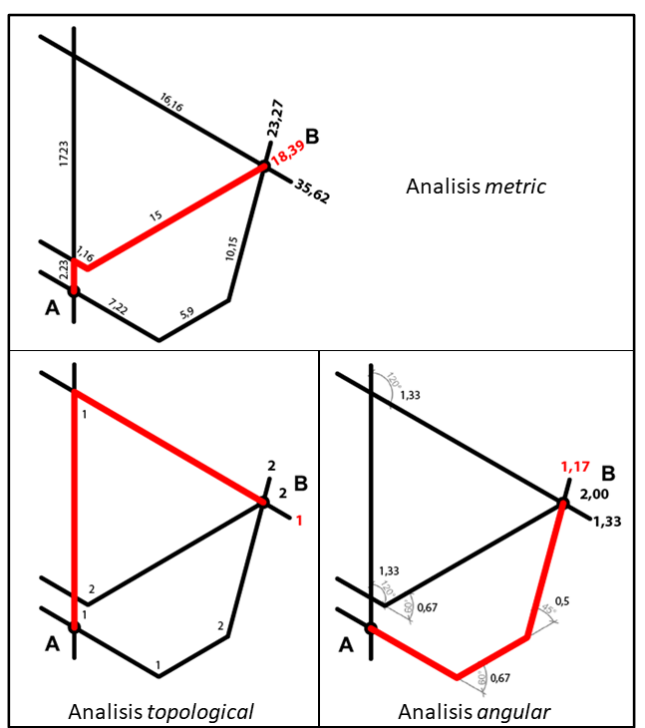

Gambar 4. Jarak terpendek secara metric (atas), topological (kiri), angular (kanan)

Sumber: Ilustrasi Penu lis berdasarkan teori Turner, 2020.

\subsection{Pemetaan Perilaku Space Syntax}

Pemetaan perilaku adalah pengamatan dengan membuat gambaran berbentuk sketsa atau diagram yang berisi area-area pengunjung dengan berbagai kegiatannya (Setiawan, 2014). Simulasi choice menampilkan pergerakan pengunjung yang tidak korespenden (tidak tertarik) dengan kondisi unik (attractor) di lapangan (Sharmin \& Kamruzzaman, 2017). Simulasi ini perlu diperkuat dan dibandingkan dengan fakta sehingga studi ini menjadi penelitian yang tidak subjektif. Oleh karena itu, teknik pemetaan perilaku diperlukan dalam mengumpulkan data faktual tentang perilaku pergerakan pengunjung. Space syntax memiliki beberapa teknik pemetaan perilaku yang terdiri dari gate count, static snapshots (placecentered mapping), traces (person-centered mapping), dan movement traces.

Teknik gate count digunakan untuk merekam aliran pengunjung di lokasi sampel dalam kawasan dalam kurun waktu tertentu (UCL Space Syntax, 2020). Gate count dapat memetakan kepadatan arus pergerakan pejalan kaki dalam suatu lokasi yang disajikan secara grafik dan statistik. Gate count dilakukan dengan menetap garis imajiner (gate) dan 
menghitung jumlah pengunjung yang melewati gate itu dalam kurun waktu yang ditentukan (lihat Gambar 5).

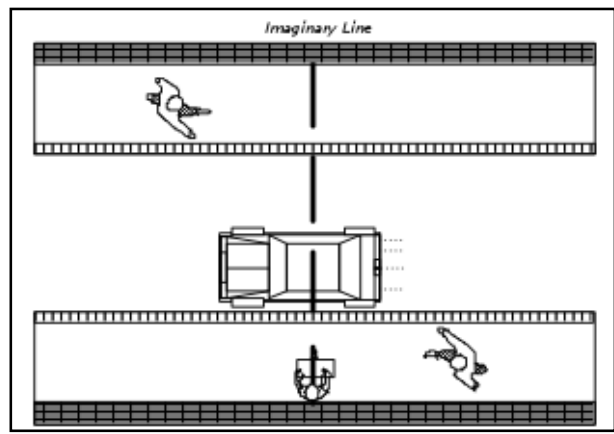

Gambar 5. Posisi Penga matan Gate Count Sumber:Al_Sayed, 2018.

\section{METODE}

Pendekatan yang digunakan dalam penelitian ini adalah pendekatan campuran sequential explanatory (Leavy, 2017). Penelitian ini dimulai dengan fase kuantitatif yang berupa kegiatan mengumpulkan data dengan metode space syntax dan analisis statistik korelasi data. Setelah itu, fase kualitatif dimulai dengan pengumpulan data teori konfigurasi ruang mal untuk bahan analisis antara pergerakan pengunjung hasil simulasi dan hasil pengamatan (Lihat Gambar 6). Metode space syntax yang digunakan dalam penelitian ini terdiri dengan simulasi choice dan pengamatan gate count (pemetaan perilaku). Simulasi choice menilai ruang spatial dengan logika dan pola sosial pengunjung secara global, kaku, dan tidak responsif terhadap faktor atraktif di lapangan. Pemetaan perilaku gate count merekam pola sosial lokal yang faktual dan responsif terhadap semua faktor yang ada di lapangan. Analisis statistik korelasi data digunakan untuk melihat tingkat kemiripan antara perilaku pengunjung dalam teori space syntax dan perilaku pengunjung di lapangan. Fase penelitian berikutnya adalah fase kualitatif yang diisi dengan kegiatan analisis grounded theory. Analisis ini dilakukan dengan tujuan menjawab fenomena dari data kuantitatif yang telah dikumpulkan dengan teori prinsip perancangan mal (Leavy, 2017). Penelitian ini dapat dilakukan secara paralel. Diagram tahapan penelitian menunjukkan terdapat 3 kegiatan yang dapat dilakukan beriringan yang ditandai dengan kurva tahap diagram berbentuk rounded rectangle (Lihat Gambar 6).

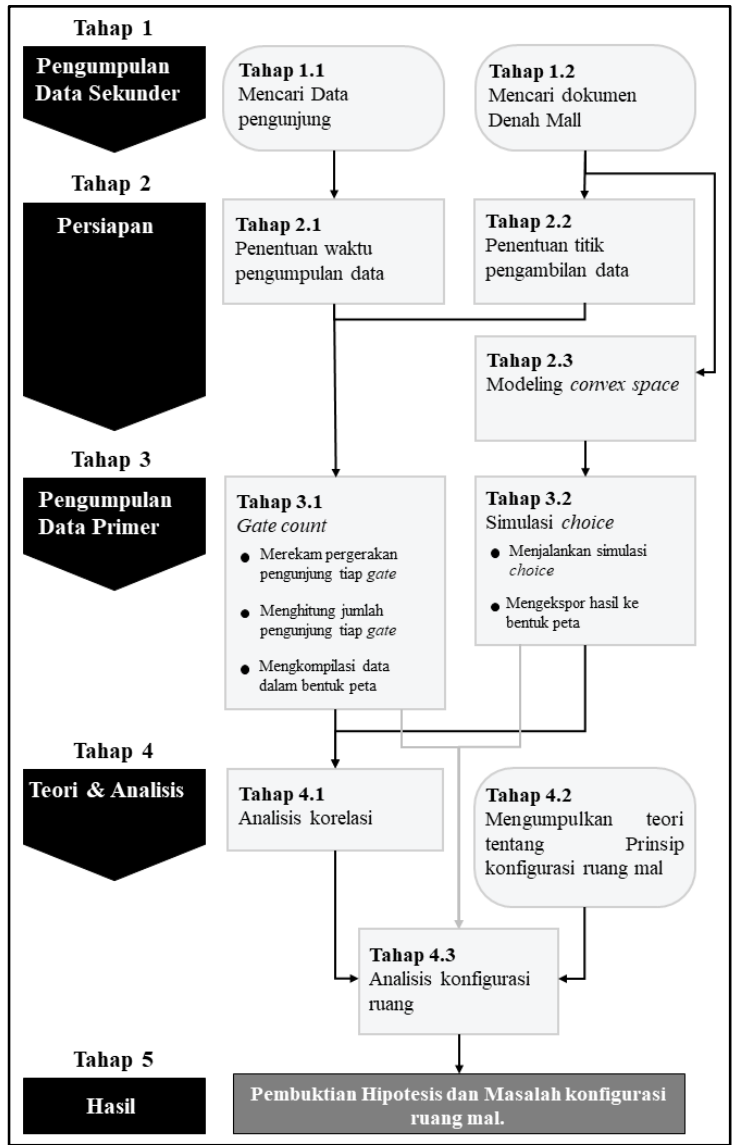

Gambar 6. Diagram Tahapan Penelitian

Wilayah pengamatan terbatas pada area sirkulasi pedestrian dalam mal. Agar dapat disimulasi dengan analisis choice, wilayah ini dimodeling ke dalam bentuk convex map. Hasil data simulasi dan hasil pengamatan berupa peta grafik denah dengan warna. Warna-warna tersebut mewakili nilai tertentu dengan keterangan rentang nilai seperti pada Tabel 1 yang dibuat berdasarkan teori Hillier dan Hanson (2003). Dalam analisis choice dan peta gate count, warna biru mewakili ruang yang jarang dilewati pengunjung, sedangkan warna merah mewakili ruang yang sering dilewati pengunjung.

Tabel 1. Tabel Rentang Nilai Warna

\begin{tabular}{|c|l|l|r|}
\hline No & Warna & Keterangan & Rentang Nilai \\
\hline 1 & & Biru Tua & $0 \%-10 \%$ \\
\hline 2 & & Biru & $10 \%-20 \%$ \\
\hline 3 & & Biru Muda & $20 \%-30 \%$ \\
\hline 4 & & Biru kehijauan & $30 \%-40 \%$ \\
\hline 5 & & Hijau Kebiruan & $40 \%-50 \%$ \\
\hline 6 & & Hijau & $50 \%-60 \%$ \\
\hline 7 & & Hijau Kekuningan & $60 \%-70 \%$ \\
\hline 8 & & Kuning & $70 \%-80 \%$ \\
\hline 9 & & Jingga & $80 \%-90 \%$ \\
\hline 10 & & Merah & $90 \%-100 \%$ \\
\hline
\end{tabular}


Waktu pengamatan dalam penelitian ini ditentukan dari data hari teramai dan data jam terpopuler. Waktu pengamatan terbaik adalah waktu puncak sesuai dengan tujuan pengamatannya yakni melihat pemanfaatan ruang pada mal (Suyanto \& Sutinah, 2015). Data rata-rata pengunjung per hari diolah dari data pengunjung PT. Matahari Indah Matahari Pontianak Indah Mall dan PT. Santosa Mitra Kalindo Januari 2019 sampai Agustus 2019. Hasil olah data rata-rata per hari adalah hari Sabtu dan Minggu sebagai hari teramai untuk kedua mal (Lihat Gambar 7).

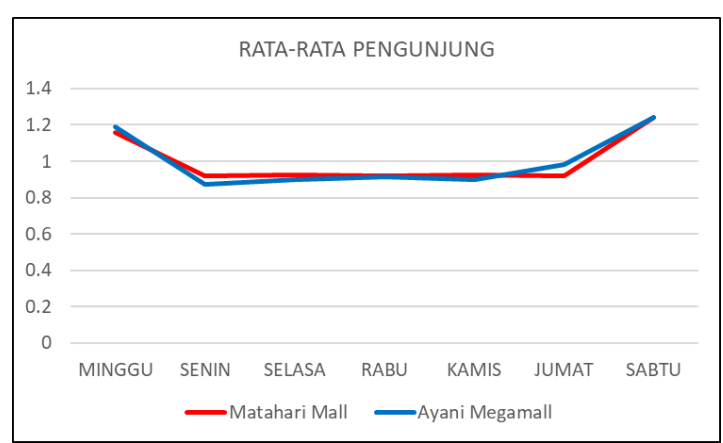

Gambar 7. Ra ta-rata Pengunjung MalPer hari

Waktu pengamatan perlu dispesifikasikan dalam rentang jam pengamatannya. Penentuan waktu (jam) pengamatan dibantu dengan data waktu populer dari Google Maps. Google Maps menyediakan informasi grafik tingkat kesibukan suatu lokasi. Grafik ini diolah berdasarkan panjangnya dengan nilai tingkat kesibukan yang memiliki jarak nilai dari 0,0 (terendah) hingga 10,0 (tertinggi). Waktu tepat untuk pengamatan dinyatakan dengan nilai tingkat kesibukan di atas 6,0. Sehingga didapatkan, waktu yang tepat untuk pengamatan di kedua mal adalah dari sore sampai malam.

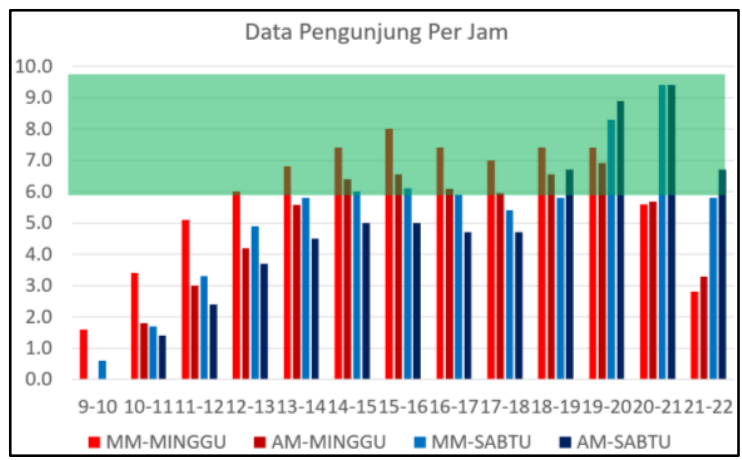

Gambar 8. Rata-rata Pengunjung Per jam Hari Sabtu dan Minggu
Titik pengamatan dirancang sehingga dapat mengkover semua area pengamatan (area sirkulasi pedestrian mal). Pengamatan dilakukan dengan merekam kondisi tiap titik pengamatan selama 5 menit dengan bantuan kamera. Di Matahari Mall, titik pengamatan ditentukan sebanyak 21 titik pengamatan, dengan distribusi tiap lantai yakni 3 titik di lantai basement, 11 titik di lantai dasar, dan 7 titik di lantai 1 (Lihat Gambar 9). Lantai 2 Matahari Mall tidak dapat diamati karena sedang dalam tahap renovasi. Di Ayani Megamall, titik pengamatan ditentukan sebanyak 57 titik dengan distribusi tiap lantai tersebar menjadi 15 titik di lantai dasar, 21 titik di lantai satu, 18 titik di lantai dua, dan 3 titik di lantai dua (Lihat Gambar 10).

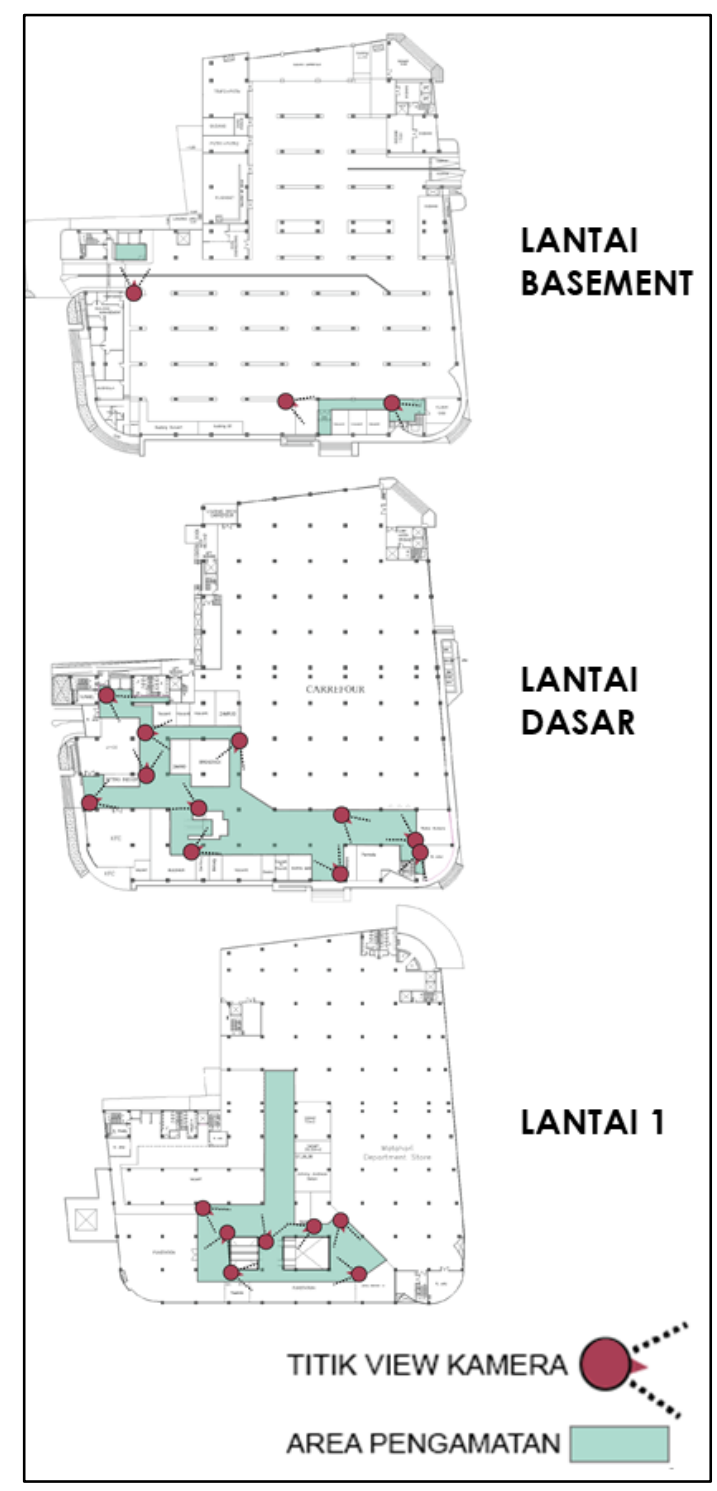

Gambar 9. Titik Pengamatan di Ma tahari Mall 


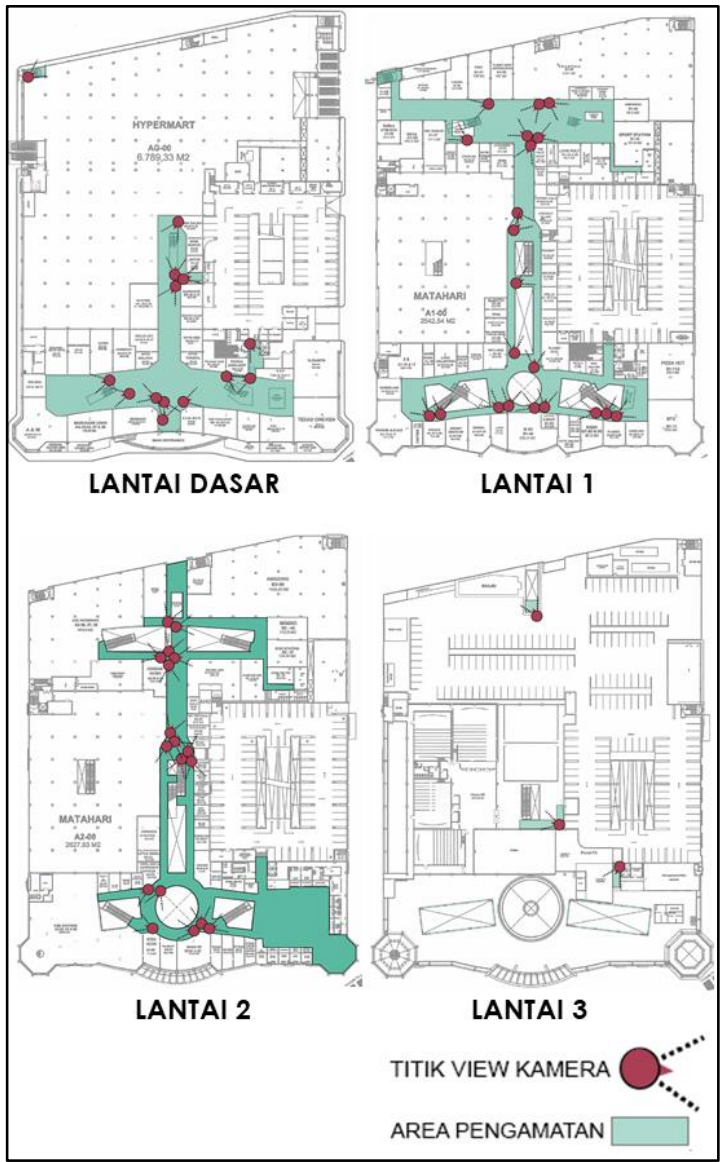

Gambar 10. Titik Pengamatan di Ayani Megamall

\section{HASIL DAN PEMBAHASAN}

Hasil temuan dari pengamatan gate count dan simulasi choice dianalisis dengan teori yang berkaitan dengan prinsip susunan konfigurasi ruang mal. Analisis ini dilakukan per lantai dengan pemaparan grafik warna hasil pengamatan dan simulasi serta grafik pergerakan pengunjung. Analisis pergerakan pengunjung didasarkan pada alasan pengunjung untuk mencapai anchor dan eskalator. Titik fokus analisis ini adalah posisi peletakan anchor, retail dan posisi eskalator.

Matahari Mall memiliki 4 tingkat lantai yang terdiri dari lantai basement, lantai dasar, lantai satu dan lantai dua. Bentuk lantai Matahari Mall berbentuk solid atau pejal (tidak panjang) mendekati bentuk persegi. Pola bentuk sirkulasi tiap lantai berbeda dan tidak beraturan. Mal ini memiliki 2 jalur akses vertikal. Lantai 1 dan lantai 2 memiliki void untuk menambah elemen visual.

Lantai basement Matahari Mall merupakan area parkir dan area servis. Lantai ini memiliki 5 retail (lihat Gambar 11). Hasil pengamatan gate count menyatakan lantai ini sepi pergerakan pengunjung. Alasan pergerakan pengunjung adalah untuk menyimpan kendaraan saat datang dan mengambil kendaraan saat pulang. Lantai ini tidak memiliki magnet (anchor) sehingga tidak ada alasan bagi pengunjung untuk berlama-lama di lantai ini. Hasil simulasi choice juga memberikan pernyataan serupa. Simulasi choice memperlihatkan kecenderungan sepinya pergerakan pengunjung pada ujung dari sirkulasi. Dari pengamatan gate count, didapatkan bahwa parkiran di basement bukan tempat parkir satu-satu nya. Ada beberapa tempat parkir lainnya yang lebih sering dipilih pengunjung. Kondisi-kondisi tersebut membuat retail di lantai ini menjadi sepi dan sulit mendapatkan calon pembeli.

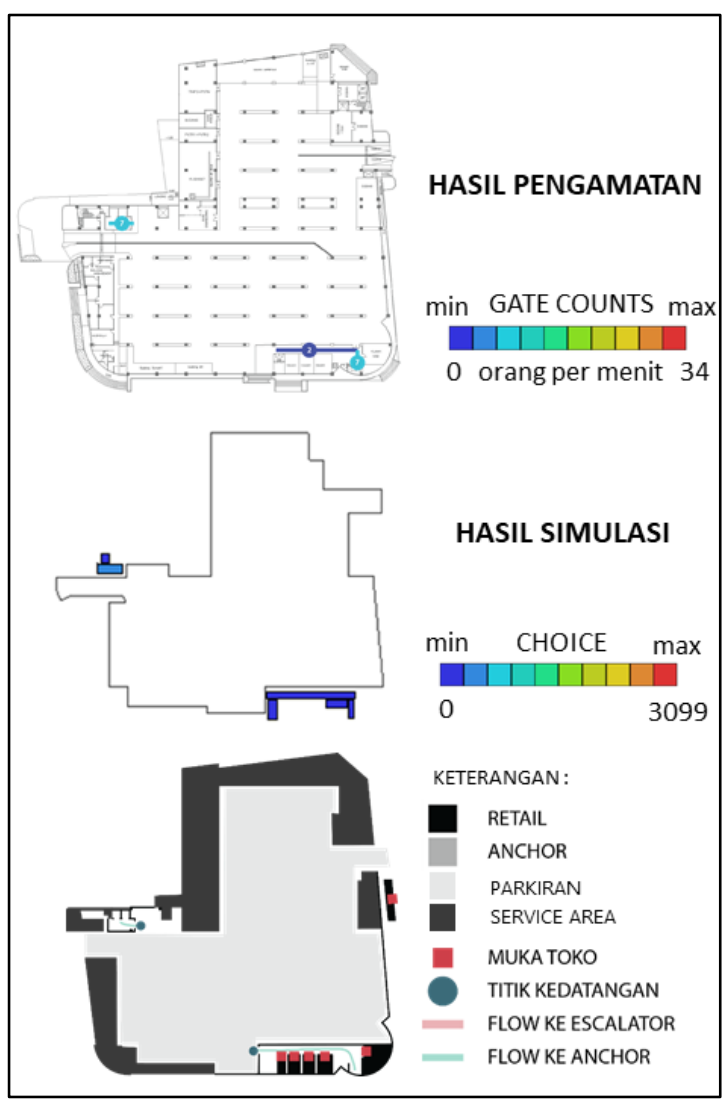

Gambar 11. Analisis Konfigurasi Ruang Matahari Mall Lantai Basement

Lantai dasar Matahari Mall memiliki 18 retail, 3 anchor, 1 titik eskalator, dan 2 elevator. Anchor (magnet) di lantai ini terletak dekat dengan titik kedatangan sehingga arus pengunjung tidak berjalan jauh untuk mencapainya. Hal ini tidak begitu baik bagi retail-retail yang terletak jauh dari titik 
kedatangan. Gate count menunjukkan 2 dari 4 titik kedatangan lebih ramai dari 2 lainnya dan eskalator berada di antara dua titik ini. Preferensi ini membuat retail-retail yang ada di antara dua kedatangan ini saja (ditandai lingkar hijau pada Gambar 12) yang diuntungkan. Di lantai ini terdapat cabang sirkulasi yang sepi (ditandai lingkar merah pada Gambar 12). Berdasarkan teori preferensi choice, bila dua jalur menuju ke tempat yang sama tetapi sudut beloknya berbeda maka pengunjung cenderung memilih jalur yang sudut beloknya kecil. Dalam kasus ini, cabang sirkulasi yang sepi ini memiliki sudut belok besar sedangkan jalur lainnya lebih kecil. Ditambah lagi, cabang sirkulasi ini lebih sempit dan tidak ada visual yang menarik. Hasil pengamatan gate count menunjukkan sangat sedikit orang yang melewati jalur ini dan retail-retail yang ada di sana tampak sepi pengunjung.

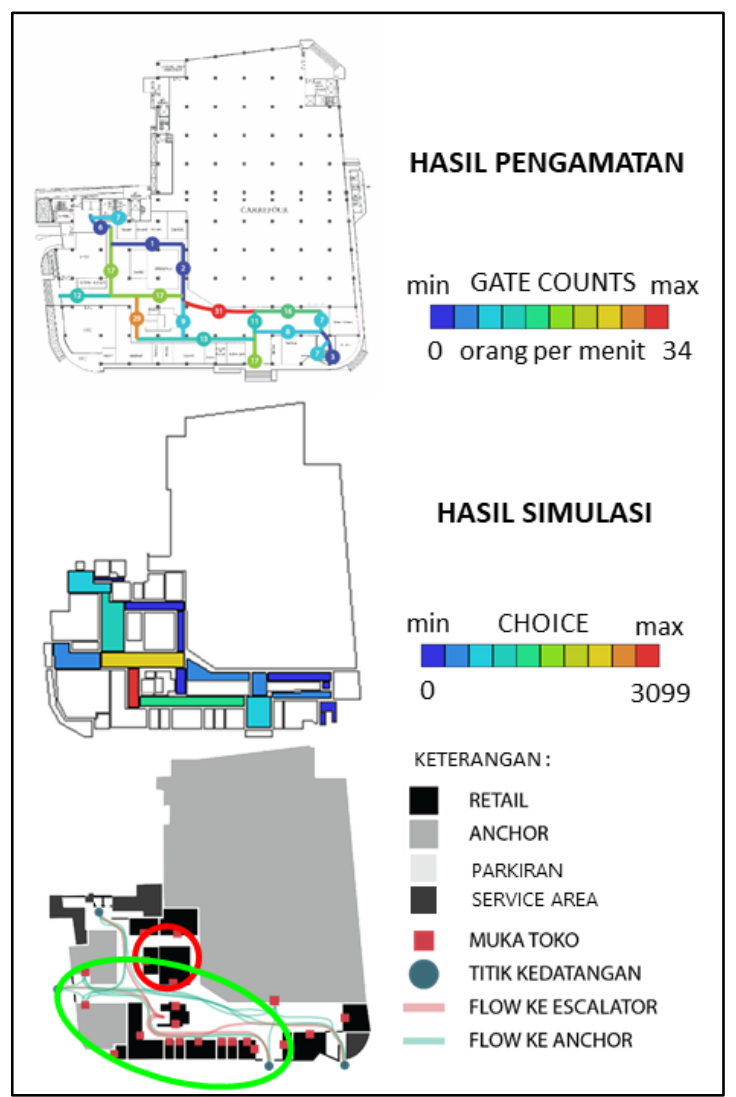

Gambar 12. Analisis Konfigurasi Ruang Matahari Mall Lantai Dasar

Lantai satu Matahari Mall memiliki 3 anchor dan 8 retail. Salah satu retail (ditandai lingkar merah pada Gambar 13) terletak di sudut pojokan. Hasil pengamatan menunjukkan sepi pengunjung yang lewat depan retail ini karena lebih sulit dijangkau. Peletakan eskalator di Matahari Mall membuat pergerakan pengunjung dari lantai bawah ke lantai atas berlangsung dengan cepat. Umumnya, semakin tinggi tingkat lantai menyebabkan semakin banyak magnetnya (anchor). Sirkulasi yang langsung dari lantai bawah (lantai dasar) ke atas (lantai dua) membuat lantai ini (lantai satu) menjadi tidak terjelajahi. Peletakan eskalator yang ideal untuk mal adalah jenis susunan interrupted flow (KONE, 2014). Susunan ini mendukung pergerakan ke lantai atas dengan memberikan pengunjung paparan view retailretail sepanjang jalan. Susunan ini membuat peluang bagi pengunjung untuk membeli tanpa terencana akan semakin tinggi dan penjualan retail akan semakin meningkat. Sederet retail (lihat lingkar kuning pada Gambar 13) memiliki potensi calon pembeli lebih bila anchor di depannya membuat akses masuk menghadap deretan retail ini.

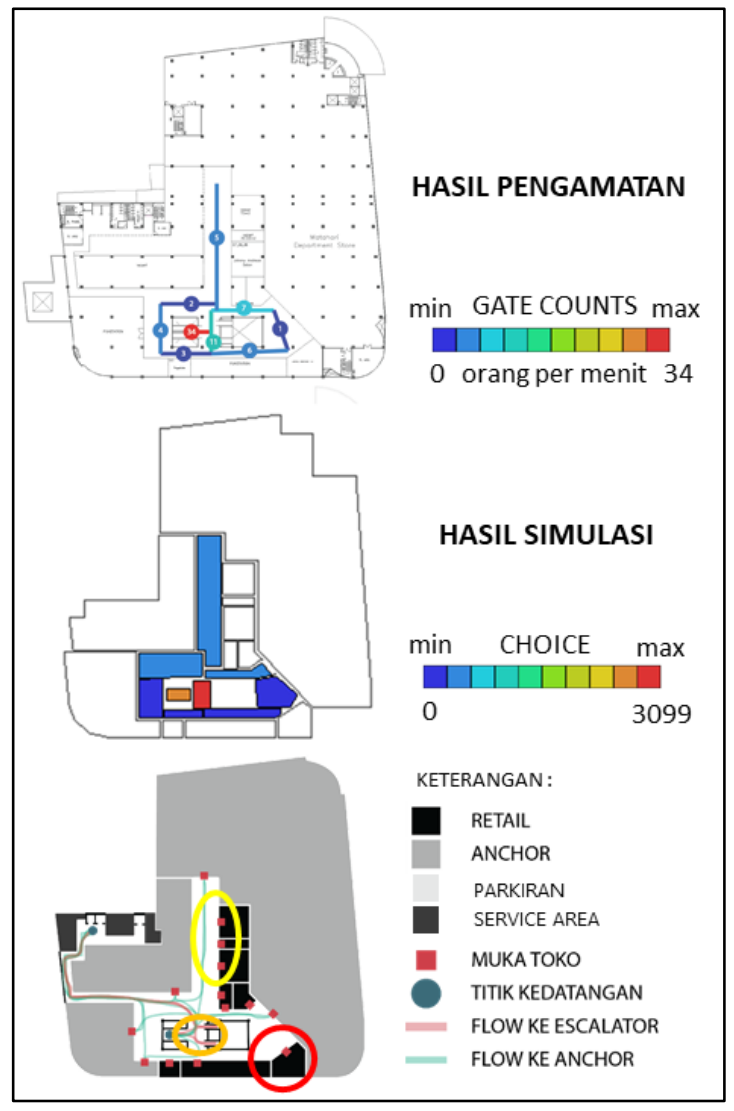

Gambar 13. Analisis Konfigurasi Ruang Matahari MallLantaiSatu

Lantai dua Matahari Mall memiliki 4 anchor dan satu retail. Pada masa pengamatan, lantai ini ditutup dengan alasan renovasi, sehingga pengamatan gate count tidak dapat dilakukan di 
lantai ini. Permasalahan di lantai ini adalah anchor terletak lebih dekat dengan titik kedatangan ketimbang retail. Berdasarkan hasil simulasi choice dan analisis arus pergerakan ke anchor, retail ini (ditandai lingkar merah pada Gambar 14) sepi dan sulit mendapatkan calon pembeli. Bila dilihat komposisi anchor secara vertikal, komposisi anchor di Matahari Mall sudah cukup baik dengan komposisi semakin ke atas jumlah anchor semakin banyak. Komposisi seperti ini dibuat agar magnet semakin kuat untuk menarik pengunjung ke lantai atas.

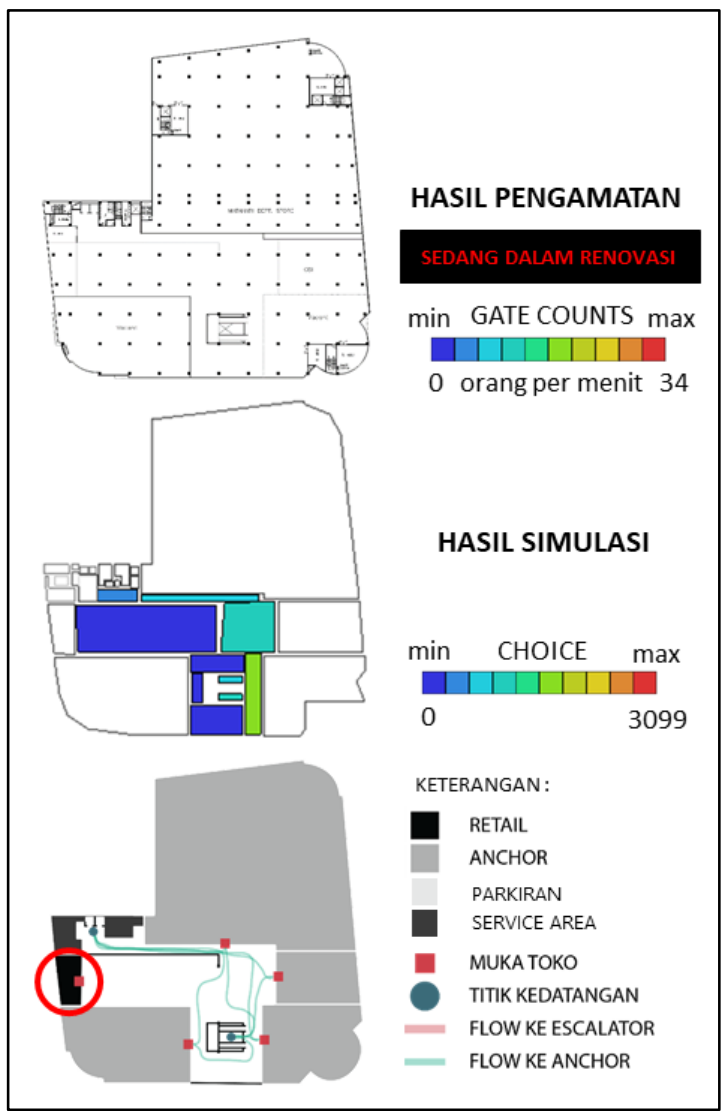

Gambar 14: Analisis Konfigurasi Ruang Matahari Mall LantaiDua

Ayani Megamall memiliki 4 tingkat lantai yang terdiri dari lantai dasar, lantai 1, lantai 2, dan lantai 3. Bentuk lantai Ayani Megamall berbentuk persegi panjang. Area pedestrian mal ini bentuk tipikal seperti bentuk $t$ atau I yang berulang dari lantai dasar hingga lantai dua. Siasat bentuk area pedestrian yang tipikal (berulang) membantu pengunjung untuk mengorientasikan diri untuk mall yang cukup luas. Mal ini memiliki 3 sampai 5 titik eskalator dan 1 titik elevator. Lantai 1 dan 2 memiliki banyak void untuk menambah elemen visual.
Lantai dasar Ayani Megamall memiliki konfigurasi ruang yang mengadopsi konsep $\mathrm{cul}$ de sac. Konsep ini meletakan anchor di ujung dan retail-retail yang berbaris sepanjang perjalanan ke anchor (lihat Gambar 15) (Rao, et al., 2018). Anchor dengan visual dan brand yang menarik membuat pengunjung terpaksa berjalan melewati retail. Visual muka retail yang men-display-kan barang jualannya akan membuat pengunjung melakukan pembelian yang tidak terencana.

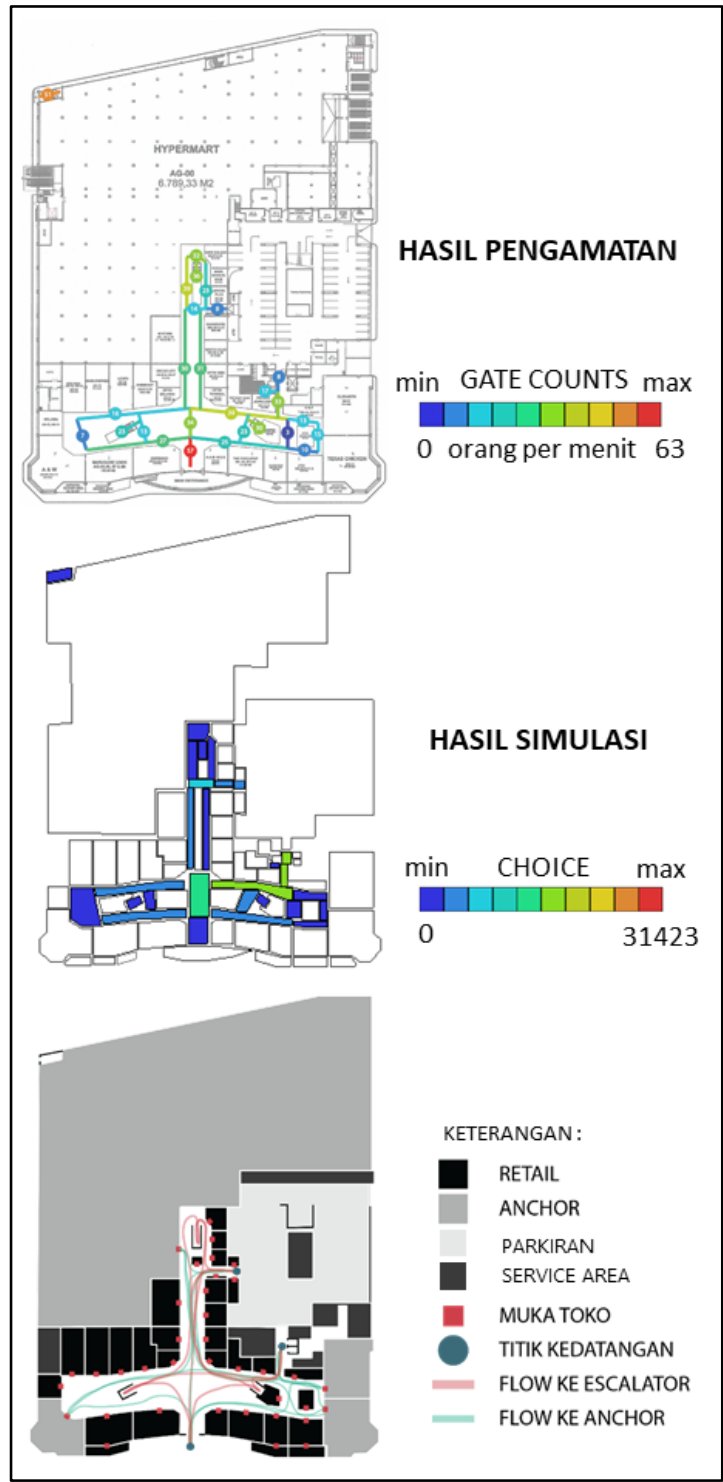

Gambar 15. Analisis Konfigurasi Ruang Matahari Mall Lantai Dasar

Lantai 1 Ayani Megamall memiliki permasalahan yang sama dengan Matahari Mall yakni cabang jalur sirkulasi yang sepi (ditandai lingkar merah pada Gambar 16). Pengamatan dan simulasi menyatakan jalur ini sepi. Cabang 
sirkulasi ini berbeda dengan yang ada di Matahari Mall. Cabang sirkulasi ini dibatasi oleh sebuah area retail tanpa dinding yang tidak menutupi visual, tidak seperti di Matahari Mall yang menutupi visual dengan dinding solid sehingga cabang sirkulasinya menjadi gang yang terpisah. Lantai ini memiliki dua retail yang terletak di pojok (ditandai lingkar jingga pada Gambar 16). Dua retail ini dapat memiliki posisi yang lebih optimal untuk mendapatkan calon pembeli bila ditukar posisi dengan anchor di samping kirinya.

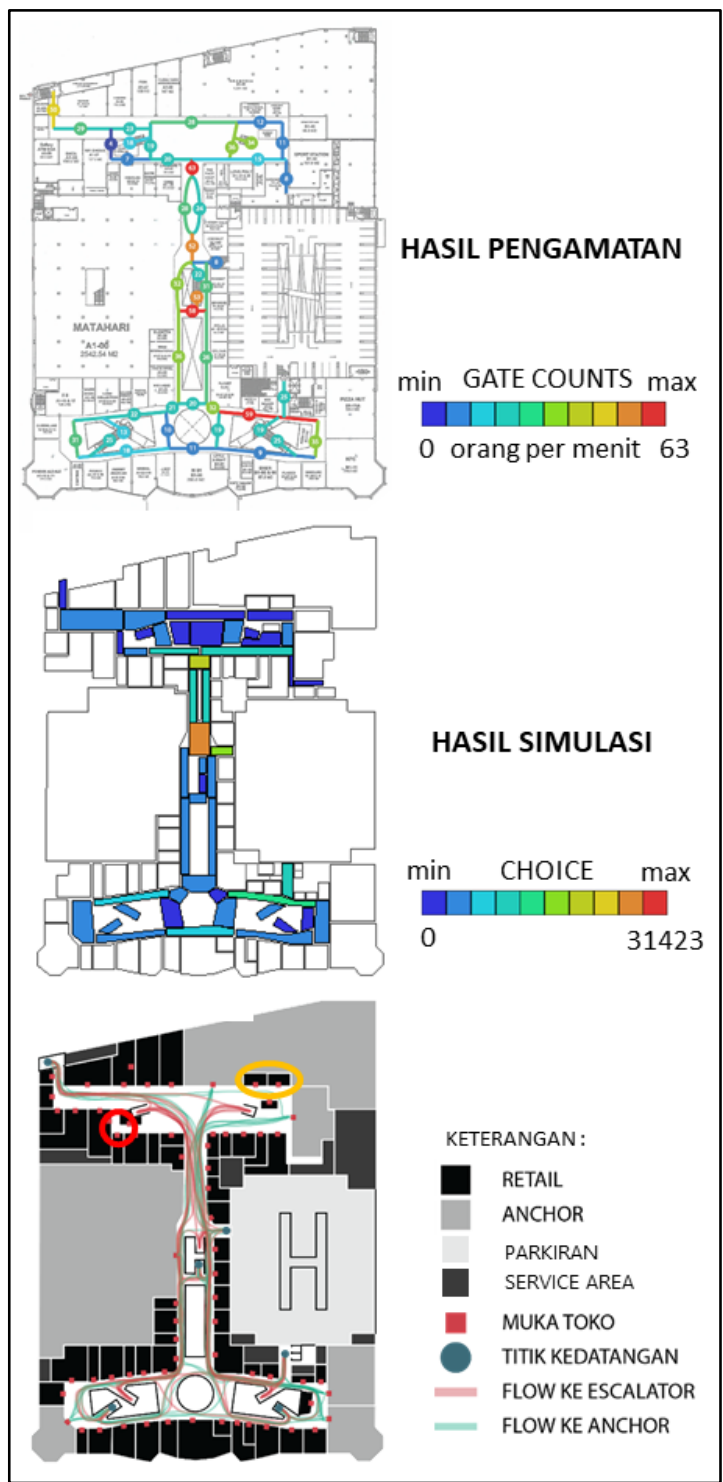

Gambar 16. Analisis Konfigurasi Ruang Matahari MallLantaiSatu

Lantai dua Ayani Megamall memiliki konfigurasi ruang yang disusun dengan konsep dumbbell. Konsep ini dinamakan dumbbell karena pola nya yang menyerupai dumbbell (sejenis alat olahraga untuk beban angkat berat) (Fahmy, et al., 2014). Konsep ini membuat efek ping pong yakni terciptanya kontinuitas pergerakan pengunjung seluruh retail toko terjelajahi dan tidak ada area mati (Syoufa \& Hapsari, 2014). Tengah antara dua ujung dumbbell yang berjauhan dapat ditambahkan 1 anchor agar di tengah juga dipenuhi pergerakan pengunjung. Hal ini dilakukan agar jarak antar dua anchor yang terlalu jauh tidak menghilangkan efek ping pong atau arus bolak balik pengunjung.

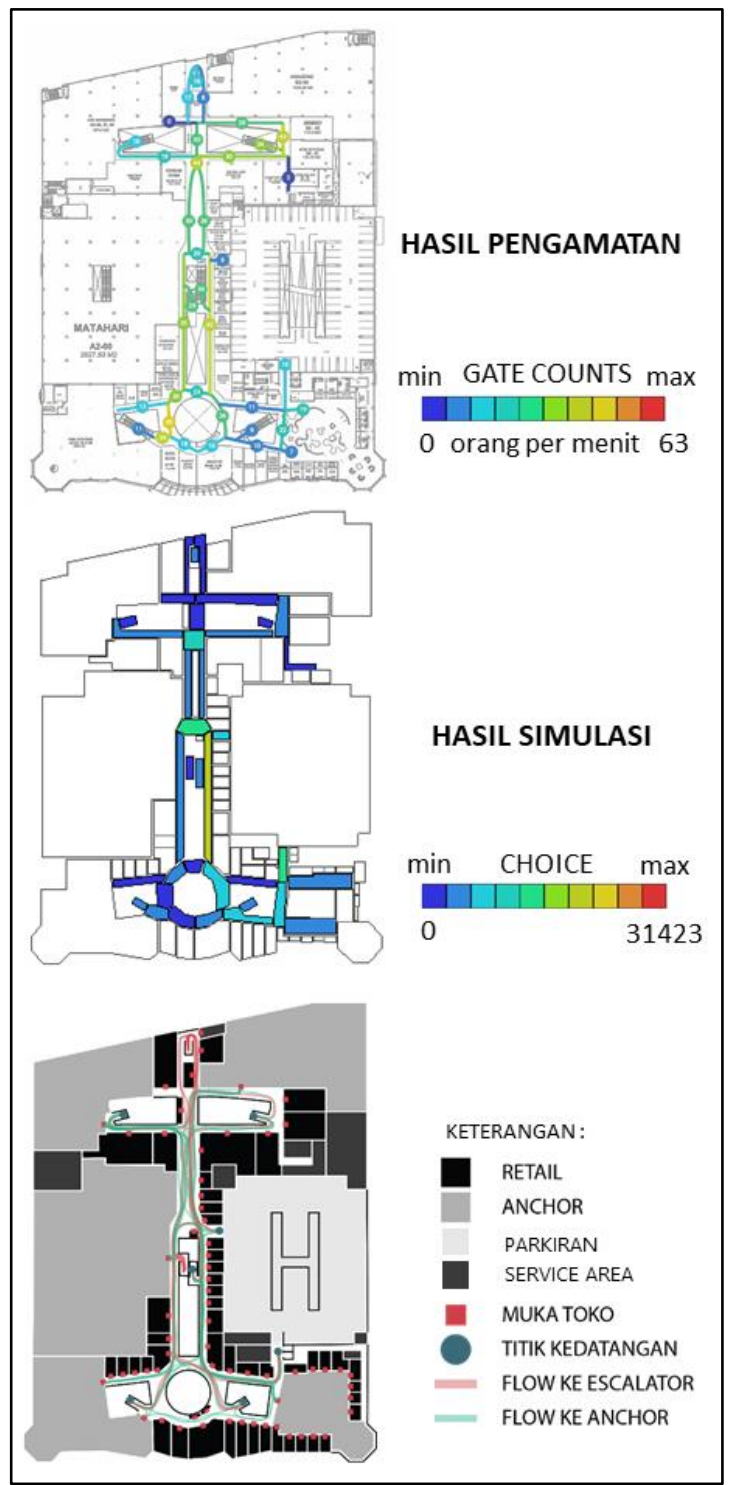

Gambar 17. Analisis Konfigurasi Ruang Matahari Mall LantaiDua

Lantai 3 Ayani Megamall merupakan lantai untuk servis dan pengelolaan. Lantai ini memiliki 2 anchor dan tidak ada retail. Area parkir di lantai ini lebih luas dari semua lantai 
lainnya. Lantai ini memiliki mushola yang dapat menjadi alasan pergerakan pengunjung. Hasil simulasi choice menunjukkan lantai ini sepi, tetapi hasil pengamatan menunjuk lantai ini tidak begitu sepi karena adanya anchor di lantai ini.

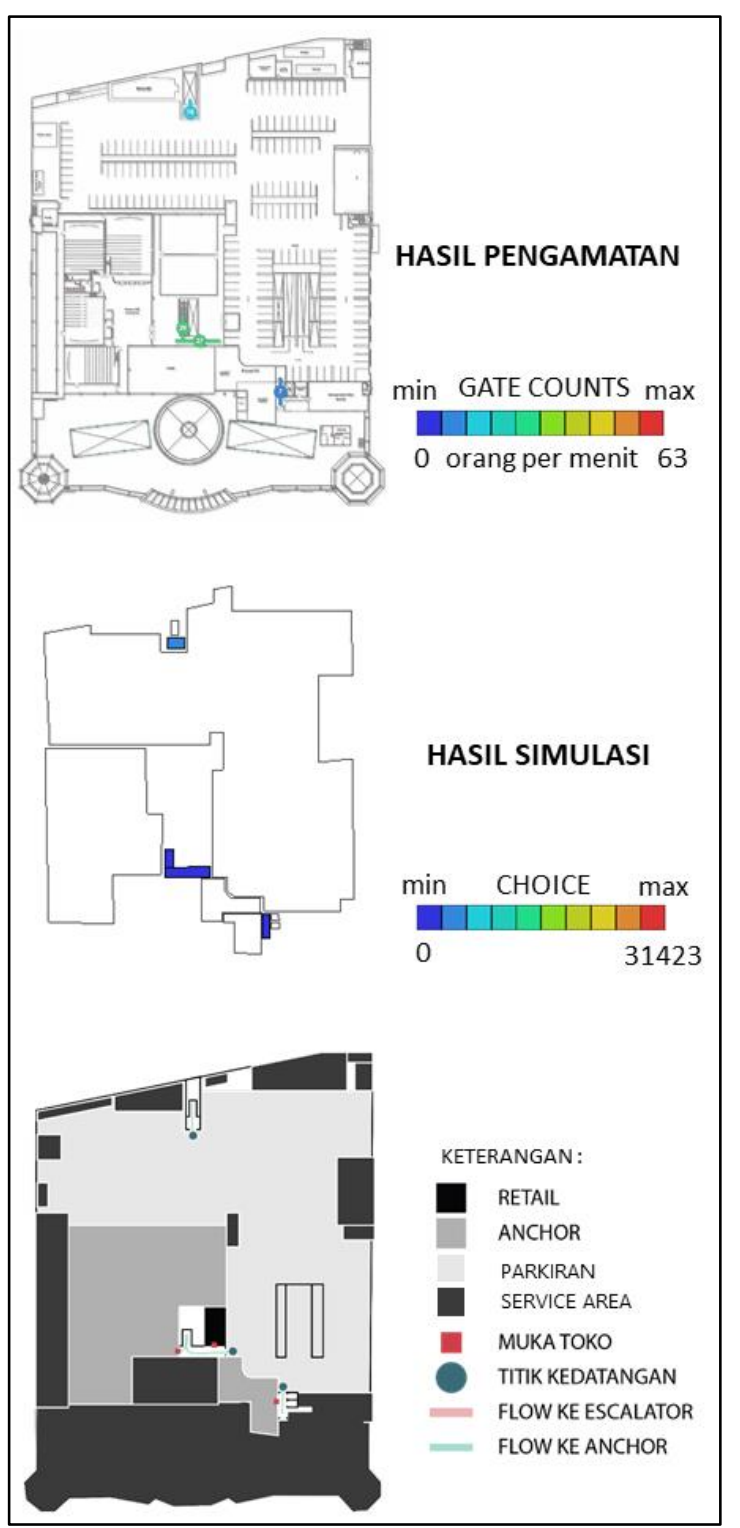

Gambar 18. Analisis Konfigurasi Ruang Matahari Mall LantaiTiga

Studi ini juga menganalisis konfigurasi ruang dari segi hubungan dan kemiripan pergerakan pengunjung simulasi choice dan pengamatan gate count. Analisis ini menggunakan statistik korelasi dengan koefisien korelasi sebagai indikator penilaian. Nilai koefisien korelasi choice dan gate count di Matahari Mall adalah 0.66 (Lihat Gambar 19 Atas). Nilai ini dapat diterjemahkan bahwa ada kemiripan yang cukup tinggi antara hasil choice dan gate count. Pola pergerakan pengunjung di Matahari Mall yang ditunjukkan dalam simulasi choice maupun gate count sama-sama tidak responsif terhadap atraktif atau magnet. Berdasarkan teori tenant mix, peletakan anchor yang baik membuat pengunjung menjelajahi semua tempat karena tertarik oleh magnet (anchor). Peletakan anchor (magnet) di Matahari Mall tidak berhasil mengubah pergerakan pengunjung untuk melewati retail-retail. Di sisi lain, nilai koefisien korelasi choice dan gate count di Ayani Megamall adalah 0.21 (Lihat Gambar 19 bawah). Nilai ini diterjemahkan bahwa pergerakan pengunjung dari hasil gate count dan simulasi choice memiliki tingkat kemiripan yang rendah. Perbedaan besar ini terjadi karena pola pergerakan pengunjung di simulasi choice bergerak tanpa tertarik oleh magnet sedangkan pola pergerakan pengunjung di lapangan sangat tertarik oleh magnet. Titiktitik sirkulasi yang bernilai rendah di simulasi choice dapat menjadi ramai di kenyataan (gate count) karena peletakan anchor di Ayani Megamall berhasil mempengaruhi pergerakan pengunjung.

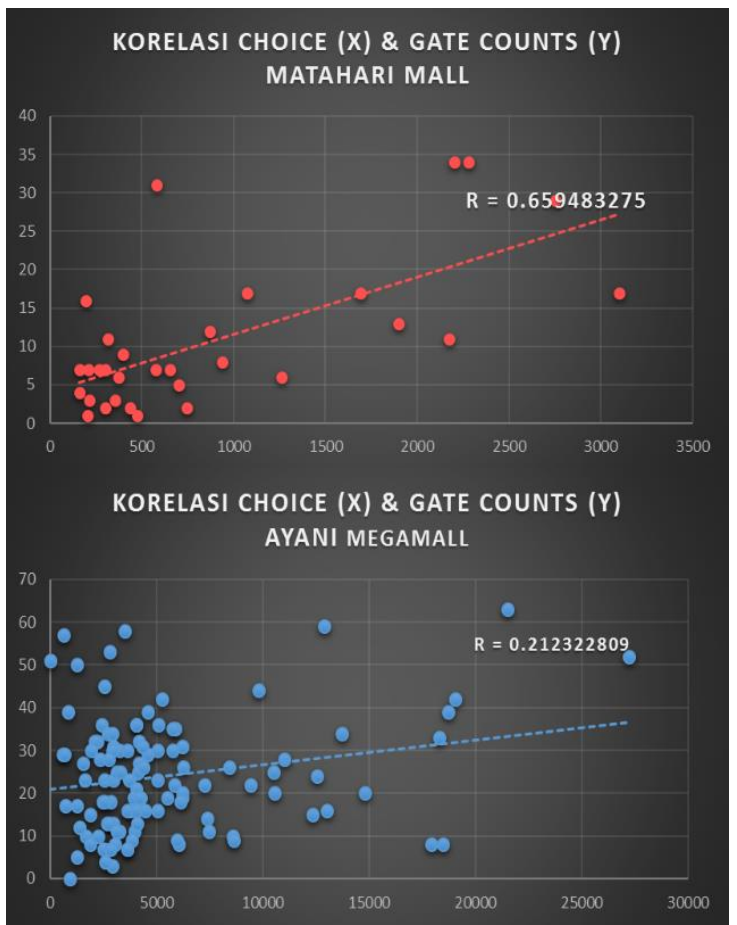

Gambar 19. Diagram Pencar Korelasi Choice dan Gate Count 


\section{KESIMPILAN}

Penelitian ini mempelajari dan menguji peran konfigurasi ruang Matahari Mall dan Ayani Megamall untuk menemukan jawaban dari masalah perancangan mal secara spesifik pada konfigurasi ruang mal. Masalah-masalah perancangan mal yang ditemukan terdiri dari masalah peletakan anchor, masalah peletakan retail, dan masalah peletakan eskalator (jalur sirkulasi vertikal). Dalam arsitektur, perancangan fungsi bangunan mal atau sejenis perlu memperhatikan poin-poin konfigurasi ruang yang terdiri dari:

- Peletakan anchor dan retail yang sesuai dengan konsep dumbbell yang mampu menciptakan efek ping pong. Agar mal berhasil, posisi anchor diatur dengan fokus untuk menguntungkan retail.

- Peletakan eskalator perlu tidak hanya untuk kelancaran sirkulasi, tetapi juga siasat untuk menyebarkan pengunjung melewati retail-retail di mal.

- Sirkulasi pedestrian sebaiknya tidak bercabang yang tidak seimbang, sebab cabang sirkulasi yang lebih jauh, lebih besar sudut belokan, dan lebih banyak belokannya akan lebih sepi.

Arsitek dapat merancang mal lebih baik dengan bantuan space syntax. Konfigurasi ruang dari rancangan mal dapat dianalisis sebelum dibangun sehingga mal dapat menjadi lebih optimal. Pada pembahasan berisi teknik penilaian konfigurasi ruang mal menggunakan space syntax yang dapat dirangkum menjadi beberapa pedoman sebagai berikut:

1. Ruang sirkulasi diharapkan tidak memiliki nilai choice rendah atau berwarna biru kecuali ruang itu mengarah ke anchor, entrance, toilet, ruang bersifat servis dan manajemen.

2. Hasil analisis nilai choice pada retail diharapkan lebih tinggi dari nilai choice pada anchor.

3. Hasil analisis nilai choice pada eskalator diharapkan bernilai tinggi tetapi tidak lebih tinggi dari nilai choice pada retail.

4. Konfigurasi ruang mall yang baik memiliki nilai koefisien korelasi yang rendah pada korelasi antara simulasi choice dan pengamatan gate count.

\section{UCAPAN TERIMAKASIH}

Terima kasih disampaikan kepada civitas akademika Jurusan Arsitektur Fakultas Teknik Universitas Tanjungpura yang telah mendukung dari tahap penelitian hingga penyusunan artikel ini. Artikel ini merupakan bagian dari hasil penelitian skripsi program sarjana Arsitektur (SI) yang disusun oleh penulis pertama di Program Studi Arsitektur Universitas Tanjungpura.

\section{REFERENSI}

Al_Sayed, K. (2018). Space Syntax Methodology. London: University College London.

Barada, W. P., \& Mutiari, D. (2013). Analisis Space Syntax Rumah Susun Berbasis Gang Kampung. Simposium Nasional RAPI, 12(1), 58-63.

Fahmy, S. A., Alablani, B. A., \& Abdelmaguid, T. F. (2014). Shopping center design using a facility layout assignment approach. The 9th International Conference on Informatics and Systems, 9(1), 1-7.

Gregg, K. (2019). Pedestrianized Streets From Shopping to Public Space: The History and Evolution of Pedestrianization In North America From Modernism to Contemporary. Toronto: ProQuest LLC.

GSA, G. S. (2012). Circulation: Defining and Planning. California: Gensler.

Hillier, B., \& Hanson, J. (2003). The Social Logic of Space. Cambridge: Cambridge University Press.

KONE. (2014). Planning retail people flow: A Handbook For Architects, Developers, and Builders. Espoo: KONE Corporation.

Leavy, P. (2017). Quantitative, Qualitative, Mixed Methods, Arts-Based, and Community-Based Participatory Research Approaches. New York: Guilford Press.

Malherek, J. (2019). Shopping Malls and Social Democracy: Victor Gruen's Postwar Campaign for Conscientious Consumption in American Suburbia. Consumer Engineering, 1920s-1970s, 1(1), 79-98.

Moghimi, L., \& Assari, A. (2016). Redefinition of Pedestrian Route-Finding Networks as a Tool to Return Vitality and Responsiveness to Yazd Khan Plaza. Current World Environment, 11(2), 378387. 
Mustafa, F. A. (2017). Performance Assesment of Building Via Post-occupancy Evaluation: Case Study of The Building of The Architecture and Software Engineering Departements in Salahaddin University-Erbil, Iraq. Frontiers of Architectural Research, 6(3), 412-429.

Nes, A. V., \& Yamu, C. (2018). Space Syntax: A Method to Measure Urban Space Related to Social, Economic, and Cognitive Factors. The Virtual and the Real in Planning and Urban Design: Perspectives, Practices and Applications, 136-150.

Pinelo, J., \& Turner, A. (2010). Introduction to UCL Depthmap 10. London: University College London.

Rao, F., Dovey, K., \& Pafka, E. (2018). Towards a genealogy of urban shopping: types, adaptations and resilience. Journal of Urban Design, 23(4), 544-557.

Setiawan, H. B. (2014). Arsitektur Lingkungan dan Perilaku. Yogyakarta: Gadjah Mada University Press.

Sharmin, S., \& Kamruzzaman, M. (2017). Meta-analysis of the relationships between space syntax measures and pedestrian movement. Transport Reviews, 38(4), 127.

Suyanto, B., \& Sutinah. (2015). Metode Penelitian Sosial: Berbagai Alternatif Pendekatan (3rd ed.). Jakarta: Kencana.

Syoufa, A., \& Hapsari, H. (2014). Pengaruh Pola Sirkulasi Pusat Perbelanjaan Mal Terhadap Pola Penyebaran Pengunjung. Jurnal Desain Konstruksi, 13(2), 46-57.

Turner, A. (2008). Getting Serious with Depthmap : Segment Analysis and Scripting. London: University College London.

UCL Space Syntax. (2020). Gate count. Available from: https://www.spacesyntax.online/term/gate -count/ .[Diakses pada: 5 Juli 2020 